\title{
Alternanthera sessilis leaf fractions possess in vitro inhibitory activities in mammalian $\alpha$-amylase and $\alpha$-glucosidase
}

\author{
Richelle Ann M Manalo1,2*, \\ Erna C Arollado 2,3 , \\ Francisco M Heralde III ${ }^{1}$ \\ 1Department of Biochemistry and \\ Molecular Biology, College of Medicine, \\ University of the Philippines Manila, \\ Manila, Philippines \\ ${ }^{2}$ Institute of Pharmaceutical Sciences, \\ National Institutes of Health, University \\ of the Philippines Manila, Manila, \\ Philippines \\ ${ }^{3}$ Department of Pharmacy, College of \\ Pharmacy, University of the Philippines \\ Manila, Manila, Philippines
}

*Corresponding author: Richelle Ann M Manalo rmmanalo4@up.edu.ph

\section{KEYWORDS:}

Alternanthera sessilis;

Diabetes; Amylase;

Glucosidase; Acarbose https://www.pharmacy.mahidol.ac.th/journal/ (C) Faculty of Pharmacy, Mahidol University (Thailand) 2020

\begin{abstract}
Diabetes is a metabolic disorder characterized by high blood glucose levels. With its increasing prevalence leading to a global burden, the search for new sources of antidiabetic agents are needed. Plant extracts and their fractions are essential in the management of diabetes due to numerous scientific evidences of their antidiabetic activity through various mechanisms. In this study, fractions from Alternanthera sessilis (Philippine variety) was investigated for their ability to inhibit key carbohydrate-degrading enzymes related to type- 2 diabetes, specifically, $\alpha$-amylase and $\alpha$-glucosidase. The crude methanol extract of $A$. sessilis leaf was fractionated with three solvents of different polarities: water, ethyl acetate and hexane. These fractions were screened for mammalian $\alpha$-amylase and $\alpha$-glucosidase inhibitory activities in vitro, and for the presence or absence of phytochemicals. All fractions displayed inhibitory activities in porcine $\alpha$-amylase and intestinal rat $\alpha$-glucosidase, with the highest activity observed in the ethyl acetate fraction (IC50 amylase $=0.52 \pm$ $0.072 \mathrm{mg} / \mathrm{mL}$; IC50 glucosidase $=2.82 \pm 0.21 \mathrm{mg} / \mathrm{mL}$ ). This fraction also demonstrated no significant difference but lower inhibitory activity relative to acarbose (IC50 amylase $=0.0025 \pm 0.00045$ $\mathrm{mg} / \mathrm{mL}, p=0.72, \alpha=0.05$; IC50 glucosidase $=0.36 \pm 0.063 \mathrm{mg} / \mathrm{mL}$, $p=0.26, \alpha=0.05$ ). Phytochemical screening of this fraction showed the presence of carbohydrates, lipids, tannins, triterpenoids, flavonoids, and glycosides, as well as berberine and quercetin, which may have accounted for the observed enzyme inhibitory activity. In summary, A. sessilis fractions may be used as potential sources of $\alpha$ amylase and $\alpha$-glucosidase inhibitors, with the ethyl acetate fraction as the most potent.
\end{abstract}

\section{INTRODUCTION}

Diabetes is a type of metabolic, non-communicable disorder arising from impairment of insulin production and/or defects in insulin action. This results in an increased blood glucose level or hyperglycemia leading to various complications such as heart disease and stroke, kidney failure, blindness and diabetic neuropathy ${ }^{1}$. Diabetes has been considered a global burden, causing more than $80 \%$ deaths in developing countries and projected to be the 7 th leading cause of death within the next 25 years ${ }^{2}$. In the Philippines, the estimated cases of diabetes were as high as 3.7 million in 2017, with adults aged 20 and above comprising the largest 
proportion of diabetes prevalence ${ }^{3}$, threatening the workforce and economy of one's country.

One of the mechanisms to manage blood glucose levels is to inhibit the key enzymes involved in carbohydrate degradation: $\alpha$-amylase and $\alpha$-glucosidase. Alpha-amylase inhibitors delay starch digestion through binding with $\alpha$-amylase, effectively reducing the activity of the enzyme. This decreases intestinal absorption of carbohydrates and facilitates reduction of postprandial hyperglycemia. Alpha-glucosidase inhibitors also slow down absorption of carbohydrates in the intestine by retarding carbohydrate digestion, leading to decrease in postprandial blood glucose levels. Several carbohydrate enzyme inhibitors are already available in the market. However, the use of medicinal plants as sources of these inhibitors is currently explored to provide alternatives and satisfy demands ${ }^{4}$.

The biological diversity of the Philippine ecosystem gives the opportunity to harness and utilize such abundance for drug discovery, which can potentially help in improving the status of diabetes management. One of the plants traditionally used for the treatment of diabetes in Antique, Philippines is Alternanthera sessilis. It has been considered as a weed in agricultural crops ${ }^{5}$ and widely utilized as vegetable in local dishes. It has also been used in folkloric medicine to treat various ailments such as headaches, hepatitis, asthma ${ }^{6}$, fever, diarrhea, dyspepsia, and liver and spleen problems ${ }^{7}$. Scientific studies of this plant include antimicrobial ${ }^{8}$, hepatoprotective ${ }^{9}$, woundhealing ${ }^{10}$, antioxidant ${ }^{11}$, and blood component (platelet and hemoglobin) augmentation ${ }^{12}$ activities. There are also previous studies of antidiabetic activities in other countries ${ }^{13,14}$. However, the mammalian $\alpha$-amylase and $\alpha$-glucosidase activities of the local variety have not been reported in literatures.

In this study, the potential in vitro inhibitory activity of the leaf hexane, ethyl acetate and water fractions of Alternanthera sessilis in mammalian $\alpha$-amylase and $\alpha$-glucosidase was investigated. The phytochemicals responsible for these activities were also determined.

\section{MATERIALS AND METHODS}

\subsection{Collection and preparation of $A$. sessilis leaves}

The plant was obtained from San Jose, Antique every mornings of March - May and September 2016. The fresh leaves were collected and placed in a styrofoam cooler to avoid direct exposure to sunlight. The samples were garbled, washed, and air-dried. A voucher specimen, with control number: 16-04-427, was submitted to the National Museum-Philippines for proper authentication.

\subsection{Preparation of $A$. sessilis leaf crude extract and fractions}

The air-dried leaves of $A$. sessilis were milled into powder and macerated with methanol at room temperature for $24 \mathrm{~h}$. The resulting mixture was filtered and concentrated using rotary evaporator. The residue was subjected to another two rounds of extraction at room temperature for $4 \mathrm{~h}$. The extracts were pooled to produce the crude methanol extract and was used for fractionation using different solvents.

The fractionation process was based on a previous method with some modifications ${ }^{13}$. The crude methanol extract was dissolved in distilled water and extracted thrice with hexane. The hexane fraction was collected, filtered and concentrated using rotary evaporator. The aqueous layer was added with ethyl acetate and partitioned using the same procedure as above. The lower and upper layers obtained after three rounds of ethyl acetate extraction was filtered and concentrated to yield the aqueous and ethyl acetate fractions, respectively. All collected fractions were dissolved in pure dimethylsulfoxide to attain various concentrations for the in vitro inhibitory assays.

\subsection{Determination of $\alpha$-amylase and $\alpha$ - glucosidase inhibitory activities}

The $\alpha$-amylase and $\alpha$-glucosidase inhibitory assays were performed based on a method wherein the enzyme concentration and reaction times were optimized ${ }^{15}$.

For $\alpha$-amylase inhibitory assay, a $10-\mu \mathrm{L}$ fraction was mixed with $1 \mathrm{U} / \mathrm{mL}$ porcine $\alpha$ amylase and incubated for $10 \mathrm{~min}$ at $37^{\circ} \mathrm{C}$. Starch solution was added, mixed and incubated for 30 $\min$ at $37^{\circ} \mathrm{C}$. The reaction was terminated by addition of 3,5-dinitrosalicylic acid followed by incubation for $10 \mathrm{~min}$ at $95^{\circ} \mathrm{C}$. The mixture was cooled to ambient temperature and diluted with distilled water. A $150-\mu \mathrm{L}$ aliquot was added in the well and the absorbance was measured at 540 nm.

For $\alpha$-glucosidase inhibitory assay, a $10-$ $\mu \mathrm{L}$ fraction was mixed with phosphate buffer $\mathrm{pH}$ 
6.8 and $50 \mathrm{mg} / \mathrm{mL}$ intestinal acetone rat powders. The mixture was incubated for $10 \mathrm{~min}$ at $37^{\circ} \mathrm{C}$ and added with p-nitrophenyl- $\alpha$-glucopyranoside. Further incubation was conducted for $30 \mathrm{~min}$ at $37^{\circ} \mathrm{C}$ followed by addition of $0.1 \mathrm{M}$ sodium carbonate. The absorbance was measured at $405 \mathrm{~nm}$.

Control was prepared by replacing the fraction with pure dimethylsulfoxide. Sample and control blanks were prepared using the fraction and pure dimethylsulfoxide, respectively, in the absence of enzyme. Acarbose was used as positive control in both inhibitory assays.

The \% inhibition was computed based on formula below:

$$
\% \text { Inhibition }=\frac{A_{\text {control }}-A_{\text {fraction } / \text { positive control }}-A_{\text {fraction } / \text { positive control blank }}}{A_{\text {control }}} \times 100
$$

\subsection{Phytochemical screening and high performance liquid chromatography (HPLC) analysis}

Phytochemical screening was conducted based on the previous study ${ }^{16}$. The fractions were tested for the presence of metabolites including carbohydrates, lipids, proteins, saponins, tannins, terpenoids, steroids, flavonoids, alkaloids, and glycosides.

The fraction with the highest inhibitory activity in both assay was subjected to HPLC. The fraction was diluted with methanol to 10 $\mathrm{mg} / \mathrm{mL}$ and separated on Symmetry® C18 5.0 $\mu \mathrm{m}$ $3.9 \times 150 \mathrm{~mm}$ column, connected to a pre-column of Phenomenex ${ }^{\circledR} \mathrm{C} 183 \times 4 \mathrm{~mm}$. The mobile phase consisted of a linear gradient of solvent A (acetonitrile) and solvent B (water/acetic acid $97: 3 \mathrm{v} / \mathrm{v}$ adjusted to $\mathrm{pH} 2.8$ ), with the following time program: $15 \%$ A (7 min), $15-20 \%$ A (5 $\min ), 20-40 \%$ (5 min), $40 \%$ A (5 min), 40-5\% A $(8 \mathrm{~min})$. The analysis has an applied flow rate of $0.8 \mathrm{~mL} / \mathrm{min}$, injection volume of $5 \mu \mathrm{L}$ and $\mathrm{UV}$ detection of $330 \mathrm{~nm}$. Standards used for the analysis were quercetin, berberine, and genistein. All the solutions were filtered using $0.45 \mu \mathrm{m}$ PTFE syringe filter prior to injection.

\subsection{Statistical analysis}

The data were reported as mean \pm standard deviation $(n=3)$. Half maximal inhibitory concentration $\left(\mathrm{IC}_{50}\right)$ and statistical significance between the groups of in vitro inhibitory assays were computed by GraphPad
Prism 7.0 software using one-way analysis of variance (ANOVA) followed by Dunnett's multiple comparison test. Mean values were considered statistically significant when $p<0.05$.

\section{RESULTS AND DISCUSSION}

\subsection{Preparation of $A$. sessilis leaf crude extract and fractions}

The air-dried leaves of $A$. sessilis were extracted with methanol to yield the crude methanol extract, which was dark green, viscous and slightly water soluble. This was used for the subsequent extraction of the hexane, ethyl acetate and water fractions. The summary of the characteristics and percent yield of the extracts and fractions are shown in Table 1.

The hexane fraction gave the highest yield, followed by ethyl acetate and then water fractions, in agreement with the previous report 13. However, all three were of lower values compared to the cited literature $(42.1 \%, 39.7 \%$, $18.2 \%$, respectively). This result may be due to the $A$. sessilis used in the mentioned study (i.e. red variety) compared to the green variety used in the present study (Figure 1).

\subsection{Determination of $\alpha$-amylase and $\alpha$ - glucosidase inhibitory activities}

The hexane, ethyl acetate and water fractions from the crude methanol extract of $A$. sessilis leaves were analyzed for their in vitro $\alpha$ amylase and $\alpha$-glucosidase inhibitory activities.

Table 1. Characteristics and percent yield of A. sessilis L. leaves extract and its fractions.

\begin{tabular}{lcccc}
\hline Fractions/extracts & Color of extract & Water solubility & Consistency & \% Yield \\
\hline Crude methanol extract & Dark green & Slightly soluble & Viscous & 12.72 \\
Hexane fraction & Dark green & Insoluble & Viscous & 24.32 \\
Ethyl acetate fraction & Green & Insoluble & Viscous & 14.68 \\
Water fraction & Dark brown & Soluble & Powder & 13.32 \\
\hline
\end{tabular}




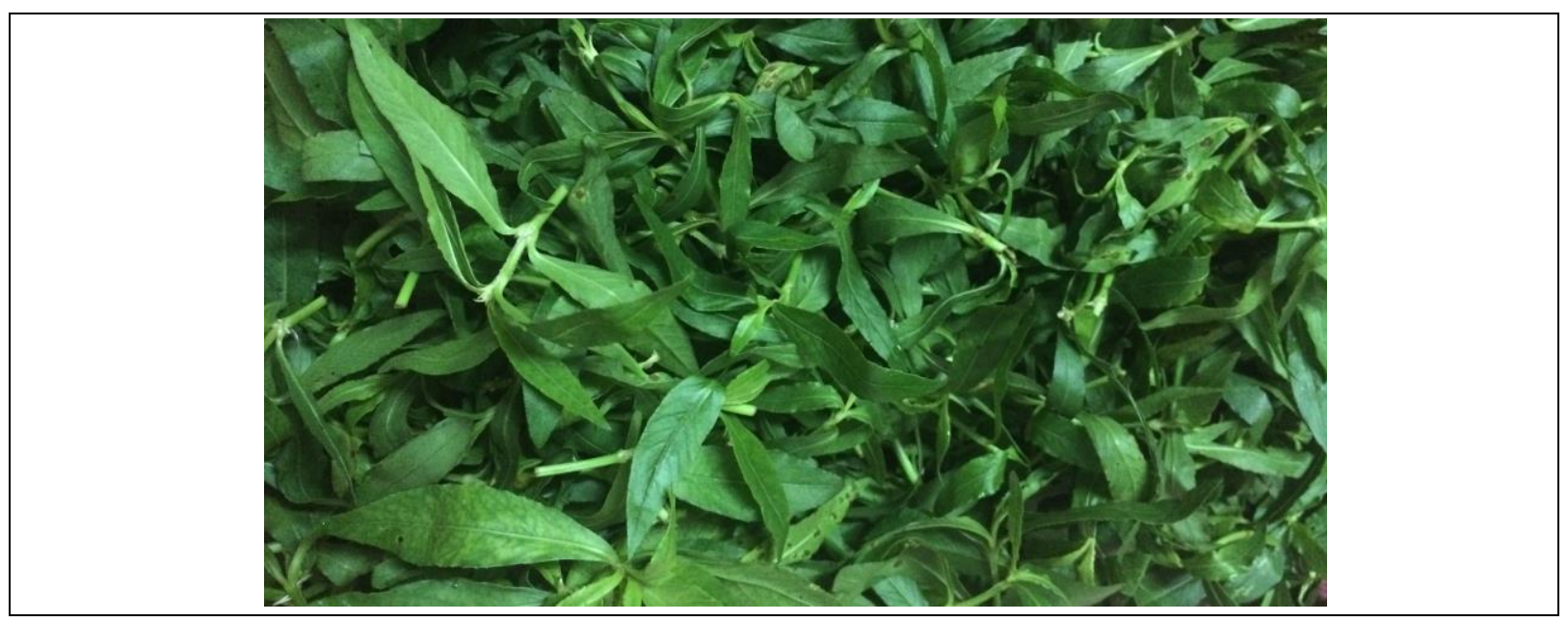

Figure 1. Green variety of A. sessilis used in this study.

Half-maximal inhibitory concentration is the concentration required to inhibit an enzymatic process by half, providing a measure of the substance's potency in enzyme-based assays ${ }^{17}$. The lower the $\mathrm{IC}_{50}$ value, the more potent inhibitor the substance is.

For the $\alpha$-amylase inhibitory assay, ethyl acetate gave the lowest $\mathrm{IC}_{50}$ among the fractions, followed by hexane and water fractions (Table 2). Statistically, only hexane $(p=0.05)$ and ethyl acetate $(p=0.72)$ fractions displayed no significant difference with acarbose (positive control). However, ethyl acetate fraction had a 200-fold higher $\mathrm{IC}_{50}$ value than acarbose, demonstrating its less effective inhibitory activity. This difference may be due to the crudeness of the fraction relative to acarbose. Thus, further purification and fractionation are necessary to utilize the potential of ethyl acetate fraction as a source of $\alpha$-amylase inhibitors.

The $\alpha$-amylase $\mathrm{IC}_{50}$ value of the water fraction obtained from this study revealed an almost similar value of $11.88 \mathrm{mg} / \mathrm{mL}$ in Aspergillus oryzae $\alpha$-amylase from the Indian variety of $A$. sessilis aerial water extract from Tamil Nadu ${ }^{18}$. However, another study of the same plant extract from Hyderabad, India showed no inhibitory activity against porcine $\alpha$-amylase ${ }^{19}$. This disparity reveals that geographical location affects the bioactivities of the same plant species, even on a country-level ${ }^{20}$. No literatures have been reported for the $\alpha$-amylase activity of $A$. sessilis hexane and ethyl acetate fractions.

The same trend of $\mathrm{IC}_{50}$ was observed for $\alpha$-glucosidase inhibitory assay: ethyl acetate fraction < hexane fraction < water fraction. Moreover, only ethyl acetate fraction showed no statistical significant inhibitory activity with acarbose $(p=0.26)$. However, its $\mathrm{IC}_{50}$ value is seven times higher than acarbose, signifying a lower inhibitory activity. This trend is consistent with the results of the glucosidase inhibitory activity of A. sessilis Red found in Malaysia ${ }^{14}$, but of lower $\mathrm{IC}_{50}$ values than those obtained in the present study. The potent inhibitory activity of the Malaysian variety may be due to the selectivity of A. sessilis fractions to Type- $1 \alpha$-glucosidase Saccharomyces cerevisiae used in their study 20 compared to intestinal rat powder $\alpha$-glucosidase in this study. Previous studies also reported that the plant extracts which exerted significant inhibitory activity in microbial $\alpha$-glucosidase failed to inhibit $\alpha$-glucosidase from rat intestinal powders ${ }^{21-22}$, suggesting that the inhibitory activity in the microbial enzyme may not necessarily apply in the mammalian form. Thus, it is more appropriate to use mammalian carbohydrate-degrading enzymes for screening of potential inhibitors before proceeding with the in vivo antidiabetic assays.

Table 2. Half maximal inhibitory concentration $\left(\mathrm{IC}_{50}\right)$ of $A$. sessilis fractions against $\alpha$-amylase and $\alpha$-glucosidase.

\begin{tabular}{lcc}
\hline A. sessilisfractions & $\mathrm{IC}_{50} \alpha$-amylase, $\mathrm{mg} / \mathrm{mL}$ & $\mathrm{IC}_{50} \alpha$-glucosidase, $\mathrm{mg} / \mathrm{mL}$ \\
\hline Hexane & $1.48 \pm 0.72$ & $7.18 \pm 1.58^{*}$ \\
Ethyl acetate & $0.52 \pm 0.072$ & $2.82 \pm 0.21$ \\
Water & $17.59 \pm 0.34^{* *}$ & $30.92 \pm 1.82^{* *}$ \\
Acarbose (positive control) & $0.0025 \pm 0.00045$ & $0.36 \pm 0.063$ \\
\hline Ances between positive control and fractions were compared by one-way ANOVA followed by Dunnett's multiple
\end{tabular}

Differences between positive control and fractions were compared by one-way ANOVA followed by Dunnett's multiple comparison test. $P$ values $<0.05$ were considered statistically significant. $*_{-}^{*} p<0.001, *_{-} p<0.01$. 
Table 3. Phytochemical screening of hexane, ethyl acetate and water fractions of A. sessilis leaves.

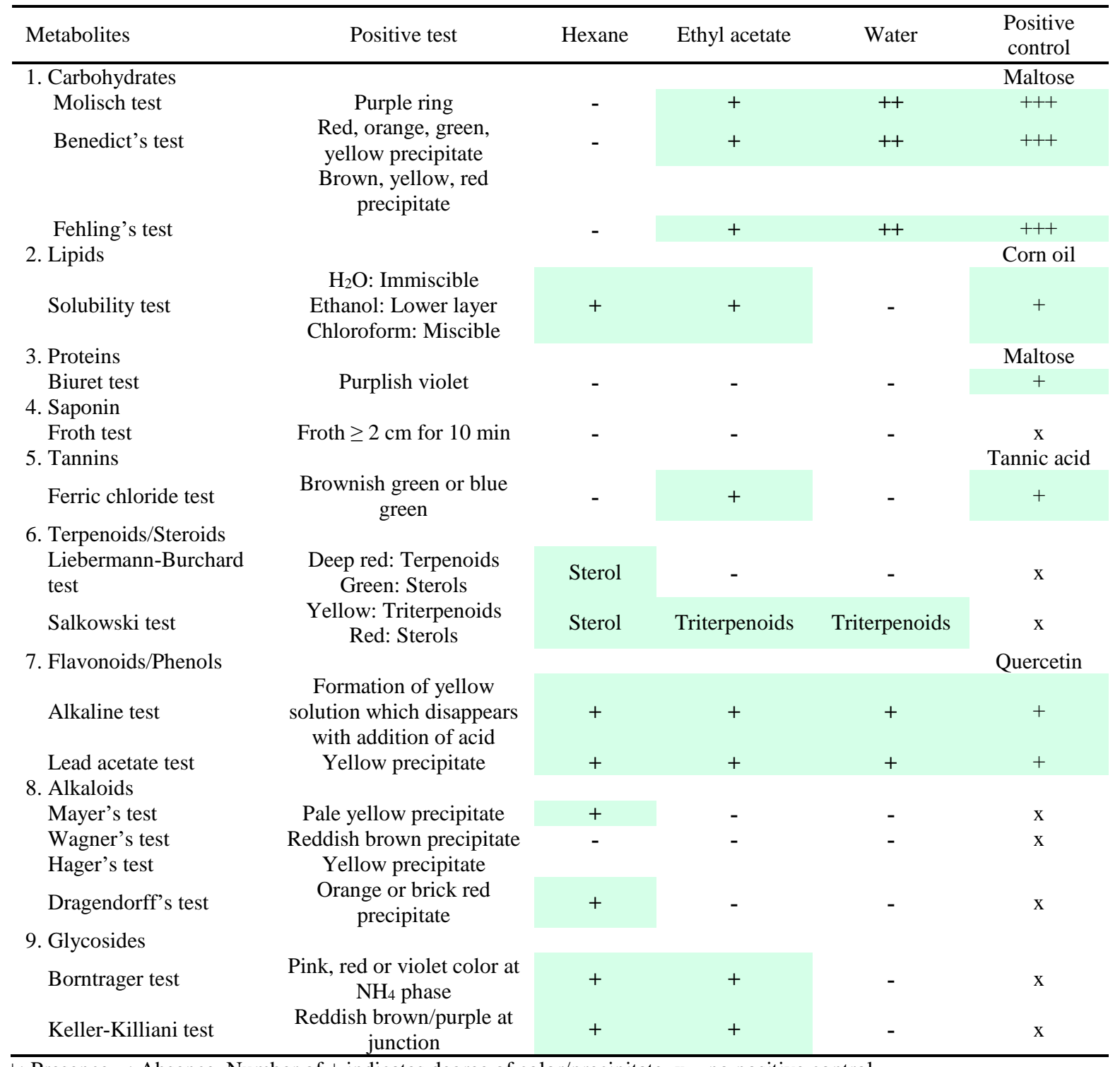

+: Presence, -: Absence. Number of + indicates degree of color/precipitate. $\mathrm{x}$ - no positive control.

\subsection{Phytochemical screening and HPLC analysis of ethyl acetate fraction}

Phytochemical screening is used to provide a preliminary data on the possible class of metabolites present in plant extracts or fractions. Table 3 shows the phytochemical screening conducted on hexane, ethyl acetate and water fractions of $A$. sessilis leaves.

Hexane fraction showed the presence of lipids, sterols, flavonoids, and glycosides. Both ethyl acetate and water fractions were positive for carbohydrates, triterpenoids, and flavonoids. However, only ethyl acetate contains tannins, lipids and glycosides compared to water fractions. The result of the phytochemical screening is slightly different compared to previous study wherein the phytochemicals present in the ethyl acetate fraction of the Malaysian red variety are phenols, terpenoids, alkaloids and secondary amines ${ }^{13}$. Aqueous extracts of $A$. sessilis from India confirmed the presence of alkaloids, flavonoids, tannins, saponins, terpenoids, phenols and carbohydrates, having more phytochemicals compared to the present study ${ }^{23}$. This signifies that the variety of A. sessilis obtained in Antique is not the same as that from Malaysia or from India. This also confirms that geographical differences affect the biochemical compounds present in the plants of the same species ${ }^{24}$.

The potent inhibitory activity of the ethyl acetate fraction may be attributed to the tannins and glycosides that is present in this fraction. 


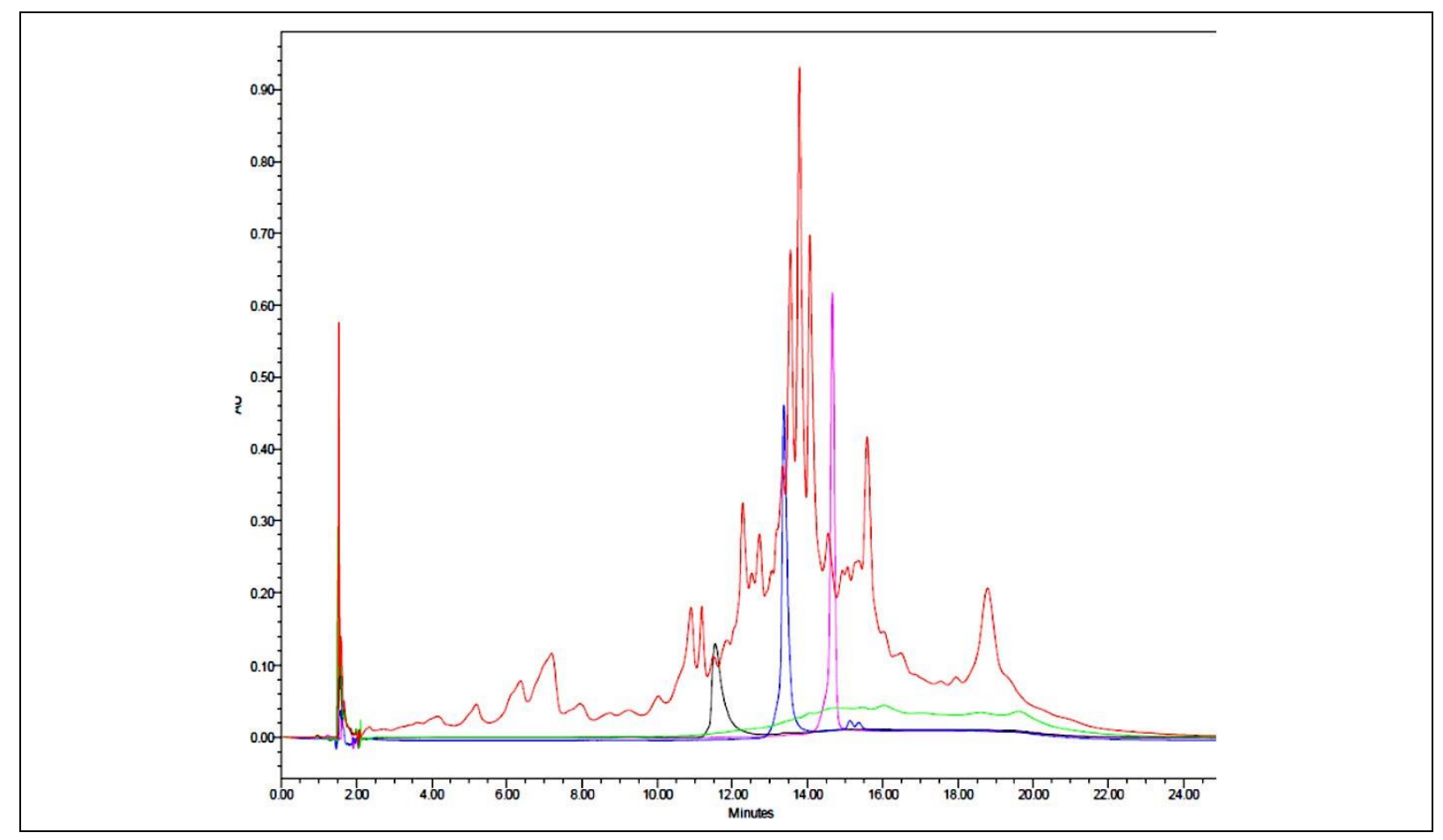

Figure 2. Chromatograms of ethyl acetate fraction (red), berberine (black), quercetin (blue), genistein (pink) and blank (green).

Glycosides, particularly deoxydifluoroglycosides, have been reported to inactivate $\alpha$-amylase and $\alpha$-glucosidase via formation of a stable glycosyl enzyme intermediate, resulting to a slow product turnover 25. Moreover, flavonoid glycosides have been shown to inhibit $\alpha$-amylase through formation of hydrogen bonds between the hydroxyl groups of individual ligand and carboxylic acid side chains of the bound cleft residues. Flavonoid glycosides also interact with $\alpha$-glucosidase through hydrogen bond, arene-arene and arene-cation formation ${ }^{26}$. These interactions result in complexation of the enzymes leading to their decreased activity.

Tannins also influence the activity of carbohydrate-degrading enzymes. It has been reported that increasing the tannin concentration increases the inhibitory activity of $\alpha$-amylase in vitro, with the inhibitory activity dependent on the size and complexity of the tannins in the extract/fractions ${ }^{27}$. Another study also displayed effective inhibition of $\alpha$-amylase in tannin-rich extracts, while removal of tannins resulted to a decrease in inhibition ${ }^{28}$. Ellagitannins and their related polygalloylglucoses are also observed to effectively inhibit rat intestinal $\alpha$-glucosidase complexes, with higher galloylglucoses units contributing to their potency ${ }^{24}$. The ability of tannins to precipitate proteins through binding of its phenolic group results to conformational changes in the carbohydrate-degrading enzymes, leading to reduced activity by association and precipitation ${ }^{24}$.

To check for specific compounds present in the ethyl acetate fraction, HPLC analysis was conducted. The chromatograms of the standards (quercetin, berberine and genistein), ethyl acetate fraction and diluent (methanol) are shown in Figure 2. Chromatogram of ethyl acetate fraction showed several peaks and two were identified as berberine and quercetin at retention times 11.542 and $13.374 \mathrm{~min}$ based on the standard chromatograms.

Quercetin and berberine were identified as natural products that can inhibit $\alpha$-glucosidase and $\alpha$-amylase in silico ${ }^{29}$. When compared with acarbose at $\mathrm{IC}_{50}=3000 \mu \mathrm{M}$, quercetin $\left(\mathrm{IC}_{50}=280\right.$ $\mu \mathrm{M})$ and berberine $\left(\mathrm{IC}_{50}=313 \mu \mathrm{M}\right)$ demonstrated a 10.7- and 9.6-fold increase, respectively, in in vivo yeast $\alpha$-glucosidase inhibitory activity. Similarly, quercetin $\left(\mathrm{IC}_{50}=500 \mu \mathrm{M}\right)$ and berberine $\left(\mathrm{IC}_{50}=170 \mu \mathrm{M}\right)$ displayed 2- to 5.9fold increase in in vivo bacterial $\alpha$-amylase inhibitory activity compared to acarbose at $\mathrm{IC}_{50}=$ $1000 \mu \mathrm{M}{ }^{29}$. Berberine has also showed attenuation of fasting blood glucose and $\mathrm{HbA1c}$ levels of patients with diabetes comparable to the effect of metformin ${ }^{30}$. They also improved body mass index and leptin/adiponectin ratio of diagnosed metabolic patients by increasing insulin sensitivity and adipogenesis ${ }^{31}$. Likewise, 
quercetin supplementation at $\geq 500 \mathrm{mg} /$ day for more than 8 weeks significantly reduced the fasting blood glucose levels of Asian participants and patients suffering from polycystic ovarian syndrome ${ }^{32}$. However, several studies have conflicting results on the antidiabetic effect of quercetin ${ }^{32}$, which needed further clinical studies for confirmation.

\section{CONCLUSIONS}

This study verified the in vitro inhibition of hexane, ethyl acetate and water fractions of the local variety of $A$. sessilis leaves in mammalian $\alpha$-amylase and $\alpha$-glucosidase. Ethyl acetate was the most potent fraction, with its activity attributed to the presence of glycosides, tannins, berberine and quercetin. However, this fraction had a lower inhibitory activity than acarbose due to its relative crudeness. Further fractionation and characterization are necessary to determine the other active compounds responsible for its activity. This can then provide valuable candidates for the development of new plantbased $\alpha$-amylase and $\alpha$-glucosidase inhibitors.

\section{ACKNOWLEDGEMENTS}

The authors would like to thank the National Institutes of Health, University of the Philippines Manila for funding this project.

\section{Conflict of interest (If any)}

The authors declare no conflict of interest in this study.

\section{Funding}

This study was funded by the National Institutes of Health-University of the Philippines Manila.

\section{Ethical approval}

This study was registered in the University of the Philippines Manila Research Grants Administration Office. No ethical approval was sought as the study did not use human subjects and/or animals.

\section{Article info:}

Received August 23, 2019

Received in revised form October 28, 2019

Accepted November 2, 2019

\section{REFERENCES}

1. Papatheodorou K, Banach M, Bekiari E, Rizzo M, Edmonds M. Complications of diabetes 2017. J Diabetes Res. 2018;3086167.

2. World Health Organization. Diabetes [document on the Internet]. 30 Oct 2018 [cited 06 Aug 2019]. Available from: https://www.who.int/news-room/fact-sheets/ detail/diabetes.

3. International Diabetes Federation Western Pacific. The Philippines [document on the Internet]. 2019 [cited on 06 Aug 2019]. Available from: https://idf.org/ournetwork/regions-members/western-pacific/members/ 116-the-philippines.html.

4. Yin Z, Zhang W, Feng F, Zhang Y, Kang W. Alphaglucosidase inhibitors isolated from medicinal plants. FSHW. 2014;3(3-4):136-74.

5. Tomaino A. Alternanthera sessilis [document on the Internet]. 13 Apr 2006 [cited on 06 Aug 2019]. Invasive Species and Assessment Protocol: U.S. National Assessments. Available from: https://www.fs.usda.gov/ Internet/FSE_DOCUMENTS/fsm91_054506.pdf.

6. Natarajan A, Leelavin KS, Jayavelu A, Devi K, Kumar BS. A study on ethnomedicinal plants of Kalavai, Vellore district, Tamil Nadu, India. J Appl Pharm Sci. 2013;3:99 - 102.

7. Srivastava A, Patel SP, Mishra RK, Vasishtha RK, Singh A, Puskar AK. Ethnomedicinal importance of the plants of Amarkantak Region, Madhya Pradesh, India. IJMAP. 2012;2:53-9.

8. Johnson M, Wesely EG, Selvan N, Kavitha MS. In vivo and in vitro anti-bacterial efficacy of $A$. sessilis (Linn.). IJPRD. 2010;2(10).

9. Bhuyan B, Baishya K, Rajak P. Effects of Alternanthera sessilis on liver function in carbon tetrachloride induced hepatotoxicity in Wistar rat mode. Indian J Clin Biochem. 2018;33(2):190-5.

10. Muniandy K, Gothai S, Tan WS, Kumar SS, Mohd Esa $\mathrm{N}$, Chandramohan $\mathrm{G}$ et al. In vitro wound healing potential of stem extract of Alternanthera sessilis. Evid Based Complement Alternat Med. 2018;3142073.

11. Mohd Hazli UHA, Abdul-Aziz A, Mat-Junit S, Chee CF, Kong KW. Solid-liquid extraction of bioactive compounds with antioxidant potential from Alternanthera sessilis (red) and identification of the polyphenols using UHPLC-QqQ-MS/MS. Food Res Int. 2019;115:241-50.

12. Arollado EC, Osi M. Hematinic activity of Alternanthera sessilis (L.) R. Br. (Amaranthaceae) in mice and rats. EISRJ. 2010;2(2):110-7.

13. Tan KK, Kim KH. Alternanthera sessilis Red ethyl acetate fractions exhibit antidiabetic potential on obese type 2 diabetic rats. Evid Based Complement Alternat Med. 2013;845172.

14. Chai TT, Khoo CS, Tee CS, Wong FC. Alphaglucosidase inhibitory and antioxidant potential of antidiabetic herb Alternanthera sessilis: Comparative analyses of leaf and callus solvent fractions. Phoog Mag. 2016;12:253-8

15. Arollado EC, Dela Torre GLT, Manalo RAM. Extraction and bioassay evaluation of selected Philippine plants for diabetes, dyslipidemia and hypertension. NRCP Terminal Report. 2017.

16. Evans WC, editor. Trease and Evans' Pharmacognosy. $10^{\text {th }}$ Edition. California:William \& Wilkins; 1972.

17. Aykul S, Martinez-Hackert E. Determination of halfmaximal inhibitory concentration using biosensor-based protein interaction analysis. Anal Biochem. 2016;508:97-103.

18. Jannathul F, Lalitha P. Assessment of $\alpha$-amylase inhibitory action of some edible plant sources. IJLS. 2016;4(3):1-7.

19. Tiwari AK, Jyothi AL, Tejeswini VB, Madhusudana K, Kumar DA, Zehra A, Agawane SB. Mitigation of starch 
and glucose-induced postprandial glycemic excursion in rats by antioxidant-rich green-leafy vegetables' juice. Phcog Mag. 2013;9(S1):S66-S73.

20. Muraina IA, Adaudi AO, Mamman M, Kazeem HM, Eloff JN. Effects of geographical location on the yield and bioactivity of Anoigeissus leiocarpus. J Pharmacy \& Bioresources. 2008;5(2):68-72.

21. Shai LJ, Magano SR, Lebelo SL, Mogale AM. Inhibitory effects of five medicinal plants on rat alphaglucosidase: comparison with their effects on yeast alpha-glucosidase. J Med Plant Res. 5(13):2863-7.

22. Babu KS, Tiwari AK, Srinivas PV, Ali AZ, China RB, Rao JM. Yeast and mammalian $\alpha$-glucosidase inhibitory constituents from Himalayan rhubarb Rheum emodi Wall. ex Meisson. Bioorg Med Chem Lett. 2004;14:3841-5.

23. Lalitha Sree T, Vijayalakshmi K. Phytochemical screening and qualitative analysis of bioactive components in various extracts of Alternanthera sessilis Linn leaves. IJCPS. 2016;4(5):242-6.

24. Sampaio BL, Edrada-Ebel R, Da Costa FB. Effect of the environment on the secondary metabolite profile of Tithonia diversifolia: a model for environmental metabolomics of plant. Sci Rep. 2016;6:29265.

25. Braun C, Brayer GD, Withers SG. Mechanism-based inhibition of yeast $\alpha$-glucosidase and human pancreatic $\alpha$-amylase by a new class of inhibitors 2-Deoxy-2,2difluoro- $\alpha$-glycosides. J Biol Chem. 1995;270:2677881.

26. Hua F, Zhou P, Wu HY, Chu GX, Xie ZW, Bao GH.
Inhibition of flavonoid glycosides from Lu'an GuaPian tea on $\alpha$-amylase and $\alpha$-glucosidase: molecular docking and interaction mechanism. Food Funct. 2018;9(8):4173-83.

27. Barrett A, Ndou T, Hughey CA, Straut C, Howell A, Dai $Z$, Kaletunc G. Inhibition of $\alpha$-amylase and $\alpha$ glucoamylase by tannins extracted from cocoa, pomegranates, cranberries and grapes. J Agric Food Chem. 2013;61:1477-86.

28. McDougall GJ, Shpiro F, Dobson P, Smith P, Blake A, Stewart D. Different polyphenolic components of soft fruits inhibit $\alpha$-amylase and $\alpha$-glucosidase. J Agric Food Chem. 2005;53(7):2760-6.

29. Jhong CH, Riyaphan J, Lin SH, Chia YC, Weng CF. Screening alpha-glucosidase and alpha-amylase inhibitors from natural compounds by molecular docking in silico. Biofactors. 2015;41(4):242-51.

30. Yin J, Xing H, Ye J. Efficacy of berberine in patients with type 2 diabetes mellitus. Metabolism. 2008;57:712-7.

31. Yang J, Yin J, Gao H, Xu L, Wang Y, Xu L, Li M. Berberine improves insulin sensitivity by inhibiting fat store and adjusting adipokines profile in human preadipocytes and metabolic syndrome patients. Evid Based Complement Alternat Med. 2012;363845.

32. Ostadmohammadi V, Milajerdi A, Ayati E, Kolahdooz F, Asemi Z. Effects of quercetin supplementation on glycemic control among patients with metabolic syndrome and related disorders: a systematic review and meta-analysis of randomized controlled trials. Phytother Res. 2019;1-11. 